\title{
EFFECTS OF SALT STRESS ON CARBOHYDRATES, ORGANIC ACIDS AND AMINO ACID COMPOSITION OF SALT-SENSITIVE AND SALT-TOLERANT LETTUCE CULTIVARS
}

Younis, M. E.; M.N. A. Hasaneen and D. M. A. M. El-Bialy

Department of Botany, Faculty of Science, Mansoura University, Mansoura, Egypt.

\begin{abstract}
Salinization of both salt-sensitive and salt-tolerant lettuce plants with increasing doses of $\mathrm{NaCl}$, throughout the entire period of experiment induced significant increases in both glucose and fructose contents and significant decreases in sucrose content. In salt-tolerant Eskandrany cultivar, sucrose content was found either to increase significantly (at $3 \mathrm{dS} / \mathrm{m} \mathrm{NaCl}$ ), non-significant decrease (at $7 \mathrm{dS} / \mathrm{m}$ $\mathrm{NaCl})$ or to decrease significantly $(9 \mathrm{dS} / \mathrm{m} \mathrm{NaCl})$. Organic acid content (citric, oxalic and keto acids) showed significant increases in both salt-sensitive and salt-tolerant lettuce cultivars as compared with control. Proline and glycine amino acids content of both cultivars, salinized with increasing doses of $\mathrm{NaCl}$, throughout the entire period of the experiment, showed significant increases. In all cases, the magnitude of accumulation of all metabolites determined was most pronounced in salt-tolerant lettuce cultivar. The results were discussed in relation to the mechanisms of salt tolerance in plants.
\end{abstract}

Keywords: Lettuce, $\mathrm{NaCl}$, carbohydrates, amino acids, organic acids.

\section{INTRODUCTION}

Plant response to salinity is generally described in terms of relative yield as a continuous function of root zone salinity, expressed as electrical conductivity of the solution in contact with the roots (ECe) (Maas and Hoffman, 1977, Maggio et al., 2007). Tammam et al. (2008) demonstrated a remarkable variation in accumulation of different carbohydrate fractions among wheat studied organs. Salt stress has a different effect on carbohydrate contents. Some authors have reported carbohydrates accumulation in various plants under salinity condition (Parida et al., 2003 and Azooz et al., 2004). Mostafa (2004) observed that at low and moderate salinity levels, sugars and consequently the total carbohydrates are decreased. Many plants accumulate compatible osmolytes, such as proline, Gly betaine, or sugar alcohols, when they are subjected to osmotic stress (Delauney and Verma, 1993; Satoh et al., 2002). Among these, proline is the most diversely used osmolyte accumulated under osmotic stress conditions in plants (Delauney and Verma, 1993; Satoh et al., 2002). Amino acids have been reported to accumulate in higher plants under salinity stress (Ashraf, 1994; Mansour, 2000). The important amino acids include alanine, arginine, glycine, serine, leucine, and valine, together with the imino acid, proline, and the non-protein amino acids, citrulline and ornithine (Rabe, 1990; Mansour, 2000). An increase in citrate, malate, and lactate and a decrease in glycollate and glycerate have also been observed in $V$. faba roots after withholding of water (Venekamp et al., 1989; Fougere et al., 1991). In alfalfa roots and nodules subjected to salt stress, organic acids did not contribute to the restoration of the osmotic potential and osmotic adjustment, but lactate 
should be given specific attention, because its concentration was doubled after salt stress. The objectives of this study were to study, the effects of $\mathrm{NaCl}$ on carbohydrate, organic acids and amino acids contents in saltsensitive and salt tolerant lettuce plants.

\section{MATERIALS AND METHODS}

Plant material

Transplants (35-d-old) of two cultivars of Lactuca sativa; salt-tolerant cultivar (Eskandrany) and salt-sensitive cultivar (Baladi) were kindly supplied by the Horticulture Research Centre, Ministry of Agriculture, Giza, Egypt.

\section{Estimation of carbohydrates}

The method of extraction of different soluble sugars used in this investigation was patterned after those adopted by Yemm and Willis (1954) and Handel (1968). Glucose was estimated in the ethanolic extract of lettuce using the o-toluidine procedure of Fertris (1965). Fructose was estimated in the lettuce ethanolic extract using the resorcinol method of Roe (1934). Sucrose content was determined using the procedures adopted by Yemm and Willis (1954) and Handel (1968). Sucrose content was determined by first degrading reactive sucrose present in $0.1 \mathrm{~cm}^{3}$ of the ethanolic extract with $0.1 \mathrm{~cm}^{3} 5.4 \mathrm{~N} \mathrm{KOH}$ at $97{ }^{\circ} \mathrm{C}$ for $10 \mathrm{~min}$. Three $\mathrm{cm}^{3}$ of freshly prepared anthrone reagent [150 mg anthrone $+100 \mathrm{~cm}^{3} 72 \%(\mathrm{w} / \mathrm{w}) \mathrm{H}_{2} \mathrm{SO}_{4}$ ] were then added to the cooled reaction products and the mixture was heated at $97^{\circ} \mathrm{C}$ for $5 \mathrm{~min}$, cooled and the developed colour was read at $630 \mathrm{~nm}$, using spectrophotometer.

\section{Estimation of amino acids}

The method used in this investigation was essentially that adopted by Yemm and Willis (1956) as described by Hasaneen (1978). Glycine was determined using the method of Muting and Kaiser (1963). Proline was estimated using the method of Snell and Snell (1954).

\section{Estimation of organic acids}

The methods adopted for estimation of oxalic acid and citric acid were essentially those of Snell and Snell (1949). Keto acids were estimated by the method of Freidman and Haugen (1943).

\section{Time course experiment}

Homogenous transplants of lettuce (lactuca sativa L. cv. Baladi and lactuca sativa L. Cv. Eskandrany) were used. The details of the experimental setup as well as of essentially those described by El-Bialy (2005). The transplant (35-d-old) were washed thoroughly with tap water and then transplanted in a mixture of clay-loamy soil $(2: 1, \mathrm{v} / \mathrm{v})$ in pots $(30 \times 28 \times 26 \mathrm{~cm})$ all pots contained equal amounts of homogenous soil $(8 \mathrm{~kg})$. The experiments were carried out outdoor under normal day and light conditions. In all cases, treatment of lettuce transplants with $\mathrm{NaCl}$ was carried out after one week from the date of transplantation. All pots were irrigated with tap water, every three days, to maintain the soil at the field capacity throughout the experiment. The appropriate amounts of $\mathrm{NaCl}$ were calculated and recorded with irrigation water so as to maintain salinity levels at $3 \mathrm{dS} / \mathrm{m}, 7$ $\mathrm{dS} / \mathrm{m}$ and $9 \mathrm{dS} / \mathrm{m}$. For control as well as for the differently treated plants, superphosphate was applied with irrigation water as $0.8 \mathrm{~g} \mathrm{pot}^{-1}$ every three 
weeks. Samples transplantation representing the vegetative, flowering, fruiting and yield growth stages were taken after 53, 104, 155 and 177 days from the date of transplantation, respectively. The samples were used for determination of carbohydrate fractions, organic acids and amino acids fractions contents. Experimental data were subjected to one way analysis of variance (ANOVA) with post-hoc LSD (Least Significant Difference) test. A P value $<0.05$ was accepted statistically significant. Statistical analysis was performed with Statistical Package for the Social Sciences for Windows (SPSS, version 13.0, 2004, Chicago, IL, USA).

\section{RESULTS AND DISCUSSION}

\section{Changes in carbohydrate content}

Perusal of the data illustrated graphically in fig. 1 and 2, revealed that salt-sensitive and salt-tolerant lettuce cultivar salinized with low, moderate and high level of $\mathrm{NaCl}$ showed variable significant increases in both glucose and fructose contents and variable significant decreases in sucrose content, throughout the entire period of experiment. In salt-tolerant skandarany cultivar, sucrose content was found either to increase significantly (at $3 \mathrm{dS} / \mathrm{m} \mathrm{NaCl}$ ), nonsignificant decrease (at $7 \mathrm{dS} / \mathrm{m} \mathrm{NaCl}$ ) or to decrease significantly (at $9 \mathrm{dS} / \mathrm{m} \mathrm{NaCl})$.

In support of these results, carbohydrate changes are of particular importance because of their direct relationship with such physiological processes as photosynthesis, translocation, and respiration. Among the soluble carbohydrates, sucrose and fructans have a potential role in adaptation to these stresses (McKersie and Leshem, 1994; Kerepesi and Galiba, 2000).

A tentative explaination of the change in carbohydrate fractions in in salt-sensitive and salt-tolerant lettuce cultivars salinized with increasing levels of salinity throughout the entire period of the experiment, in the present study was that sucrose can act in water replacement to maintain membrane phospholipids in the liquidcrystalline phase and to prevent structural changes in soluble proteins. The role of reducing sugars (glucose and fructose) in the adaptive mechanism is more controversial, and even their accumulation can be detrimental from several points of view (Kerepesi and Galiba, 2000).

\section{Changes in organic acid content}

The retained from this study are quite clear that the salt tolerance of lactuca sativa induced significant variable accumulation of organic acids and total phenolic compound contents, throughout the entire period of the experiment (see figure 3 and 4). In general, the accumulation rate of both organic acids and total phenolic compounds in the salinized lettuce plants, throughout the entire period of the experiment showed drastic increase in salt-tolerant cultivar compared with salt-sensitive cultivar.

The observed increases in organic acids (citric, oxalic and keto acids) contents as well as in total phenolic compounds in salt- 
sensitive and salt-tolerant lettuce cultivars, throughout the entire period of the experiment, can be used as indicator in the selection of plants that will withstand saline stress through osmoregulations as reported by El-Saht (1994). Of interest in this connection, Handa et al. (1983) and Hasaneen et al. (1990) found that the concentrations of amino acids determined were increased with the degree of adaptation of tomato, French bean and maize plants to salt stress. Thus, the low tolerant French bean plants were found to accumulate less organic acids than the highly tolerant plants of maize.

El-Saht (1995) reported that keto acids, oxalic acid and citric acid contents of maize plants subjected to $100 \mathrm{mM} \mathrm{NaCl}$ showed highly significant accumulation of these acids. Accumulation of osmolytes allows osmoregulation to occur and may also stabilize macromolecules.

\section{Changes in amino acids content}

Perusal of the data presented and figure 5 and 6 revealed that proline and glycine contents of salt-sensitive and salt-tolerant lettuce plants treated with increasing concentration $\mathrm{NaCl}$ showed a significant increases, throughout the entire period of the experiment. At the highest level $(9 \mathrm{dS} / \mathrm{m}) \mathrm{NaCl}$, the proline percent of production in salt sensitive cultivars $151.90 \%$ at vegetative and $122.36 \%$ at flowering, $125.36 \%$ at fruiting and $132.54 \%$ at yield where in salttolerant cultivars the rate of accumulation of proline was $29.83 \%$ at vegetative and $22.65 \%$ at flowering, $20.21 \%$ at fruiting and $25.04 \%$ at yield stages. On the other hand, the accumulation rate of glycine in salt-sensitive cultivar was $127.05 \%$ at vegetative and $70.99 \%$ at flowering, $140.64 \%$ at fruiting and $86.46 \%$ at yield where in salttolerant cultivar the rate of accumulation of glycine was $123.23 \%$ at vegetative and $98.99 \%$ at flowering , $100.59 \%$ at fruiting and $75.23 \%$ at yield stages.

Free amino acids (proline and glycine) are known to occur widely in higher plants and normally accumulate in large quantities in response to environmental stresses (Hsu et al., 2003; Kavi Kishore et al., 2005; Ashraf and Foolad, 2007). In addition to its role as an osmolyte for osmotic adjustment, proline contributes to stabilizing sub-cellular structures (e.g. membranes and proteins), scavenging free radicals, and buffering cellular redox potential under stress conditions. It may also function as a proteincompatible hydrotrope (Srinivas and Balasubramanian, 1995), alleviating cytoplasmic acidosis, and maintaining appropriate NADP+/NADPH ratios compatible with metabolism (Hare and Cress, 1997). Hasaneen et al. (2008) reported that salinization of lettuce plants with increasing concentration of $\mathrm{NaCl}$ induced significant increases in both proline and glycine contents which appeared to be progressively higher with an increase in salinity level used. In addition, increased proline and glycine contents in both saltsensitive and salt-tolerant lettuce cultivars salinized with increasing concentration of $\mathrm{NaCl}$, throughout the entire period of the experiment is started to be possibly related with $\mathrm{NaCl}$ tolerance (Juncklang, 2005). He added, higher accumulation of amino acids, glycine and proline contents were observed with increasing $\mathrm{NaCl}$ concentrations in both plant species. 

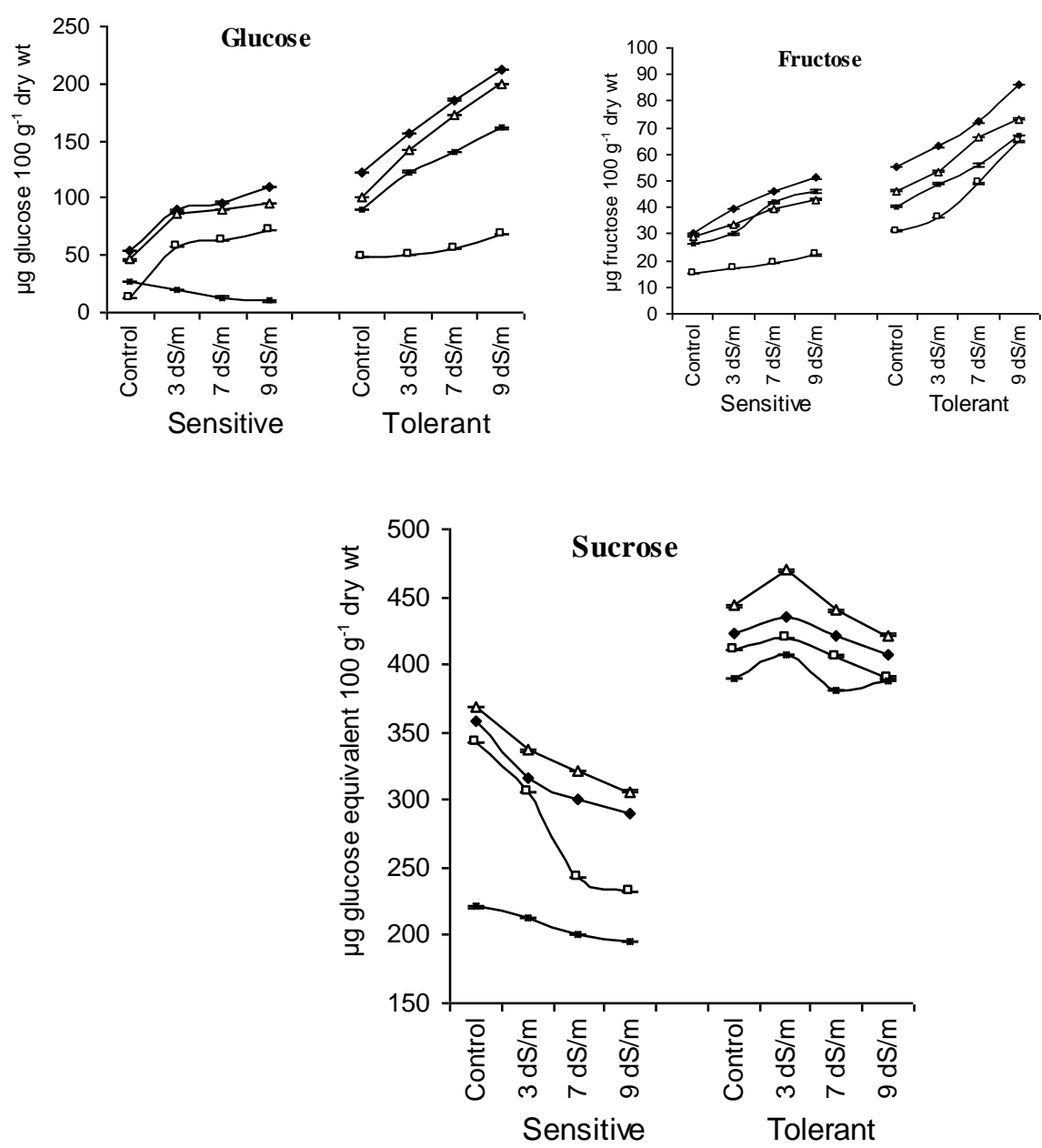

Fig. 1: The effects of three different levels of $\mathrm{NaCl}$ on soluble sugars (glucose, fructose, sucrose) of both salt-sensitive and salttolerant lettuce cultivars at four different stages (一 $\square$ vegetative, $-\downarrow$ flowering, $-\Delta-$ fruiting, $-*-$ yield). Vertical bars represent standard error $(n=8)$. 
Younis, M. E. et al.
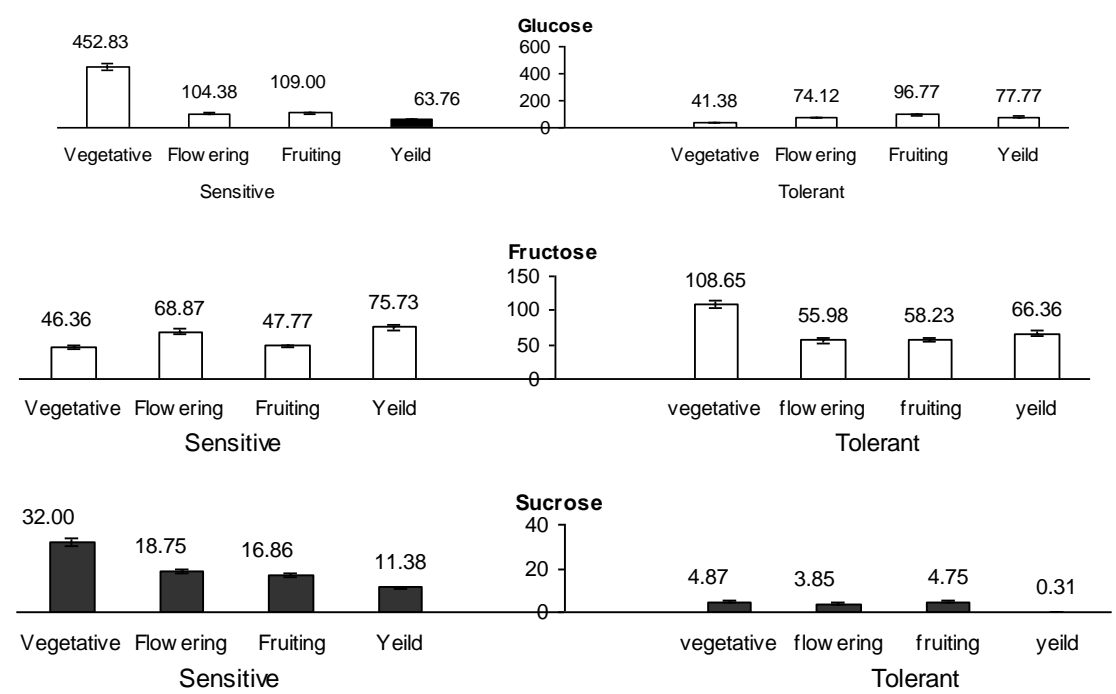

Fig. 2: Percent stimulation (PS) of both the glucose and fructose contents and percent inhibition (PI) of sucrose content of both salt-sensitive and salt-tolerant cultivars salinized with $9 \mathrm{dS} / \mathrm{m} \mathrm{NaCl}$ at vegetative, flowering, fruiting and yield stages ( $\square \mathrm{PS}, \backsim \mathrm{PI})$. Vertical bars represent standard error $(\mathrm{n}=8)$.
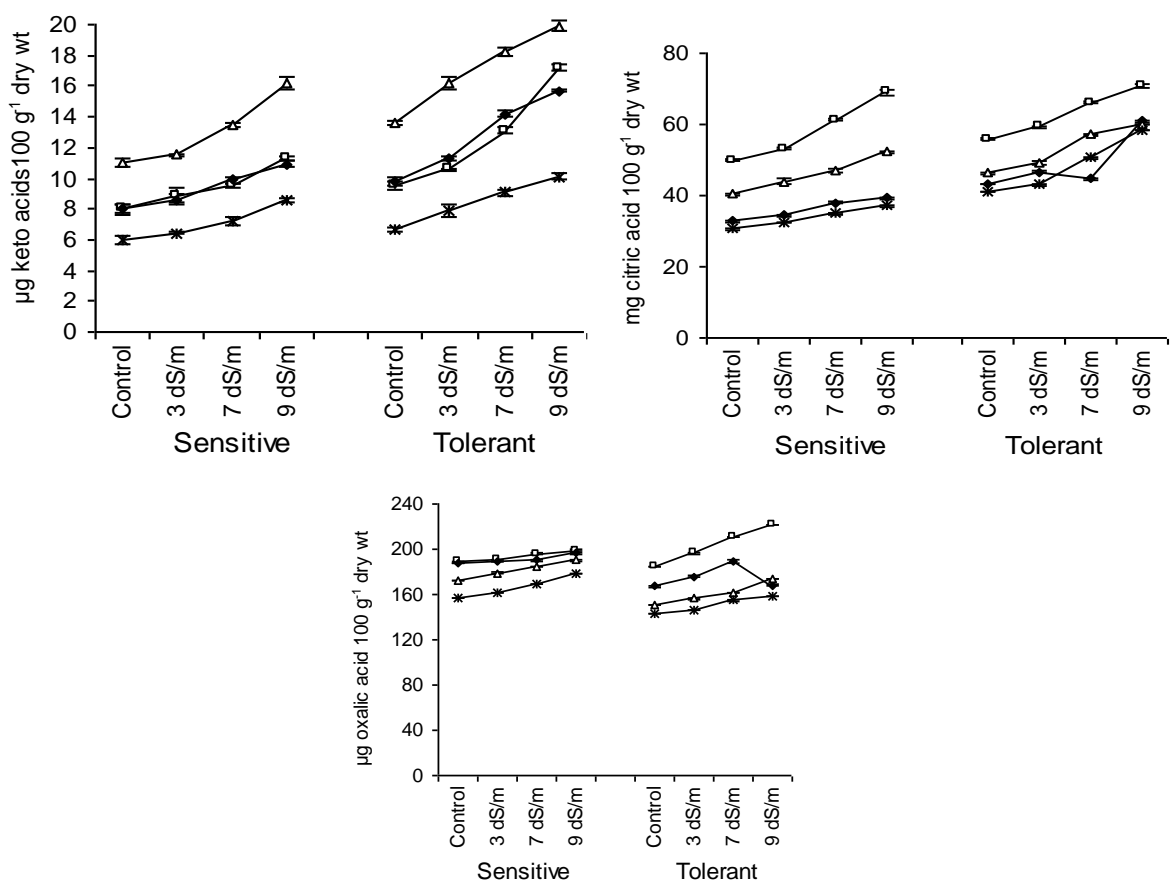

Fig. 3: The effects of three different levels of $\mathrm{NaCl}$ on organic acids (citric, oxalic and keto acids) of both salt-sensitive and salt-tolerant lettuce plants at four different stages $(-\square-$ vegetative, $-\downarrow$ flowering, $-\Delta-$ fruiting, $-*-$ yield). Vertical bars represent standard error $(n=8)$. 

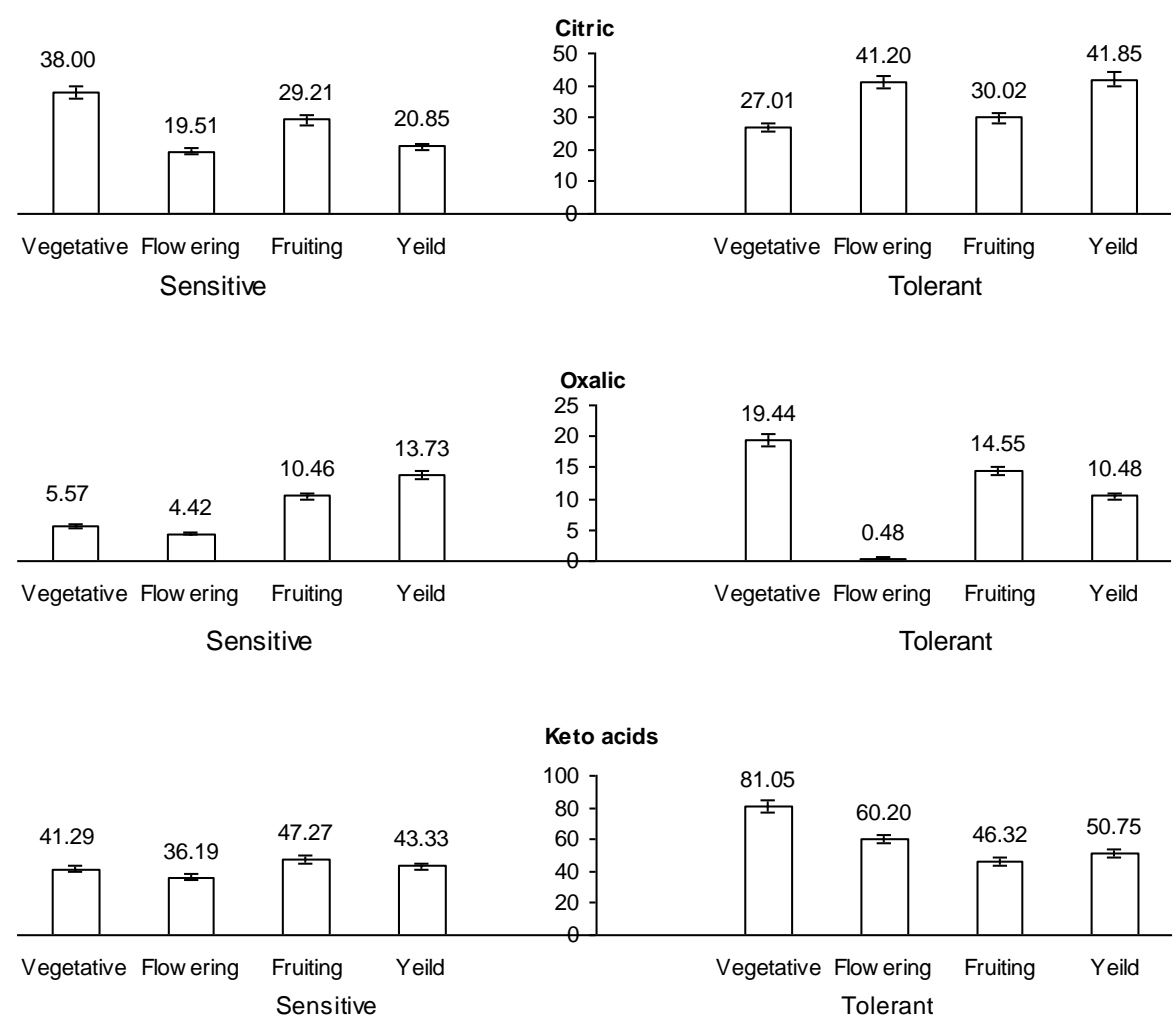

Fig. 4: Percent stimulation (PS) of organic acids of both salt-sensitive and salt-tolerant cultivars salinized with $9 \mathrm{dS} / \mathrm{m} \mathrm{NaCl}$ at vegetative, flowering, fruiting and yield stages. Vertical bars represent standard error $(n=8)$.
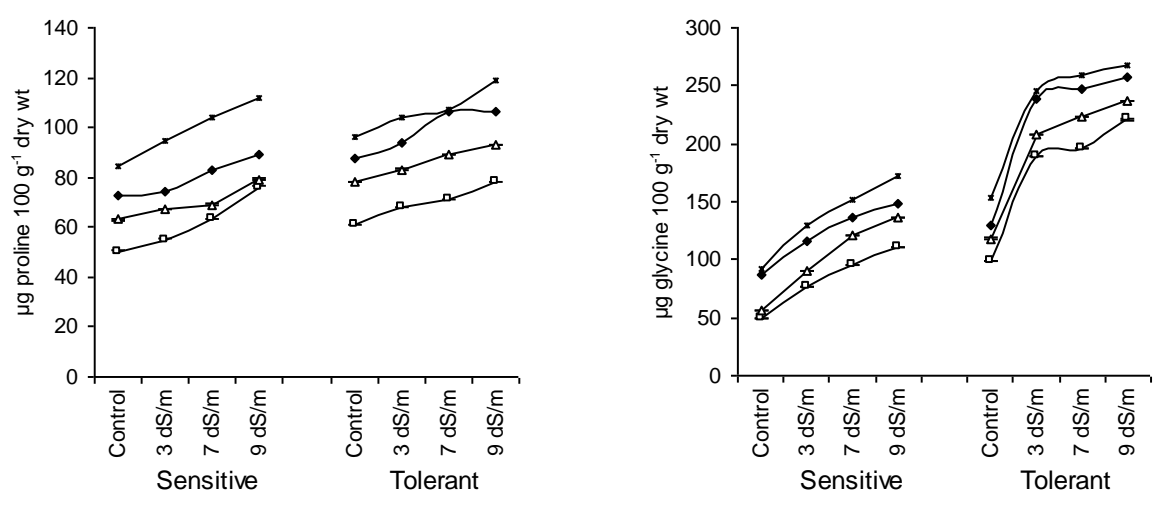

Fig. 5: The effects of three different levels of $\mathrm{NaCl}$ on amino acids (proline, glycine) contents of both salt-sensitive and salt-tolerant lettuce cultivars at different stages (一 - vegetative, $-\downarrow$ flowering, $-\Delta-$ fruiting, $-*-$ yield). Vertical bars represent standard error $(n=8)$. 
Younis, M. E. et al.
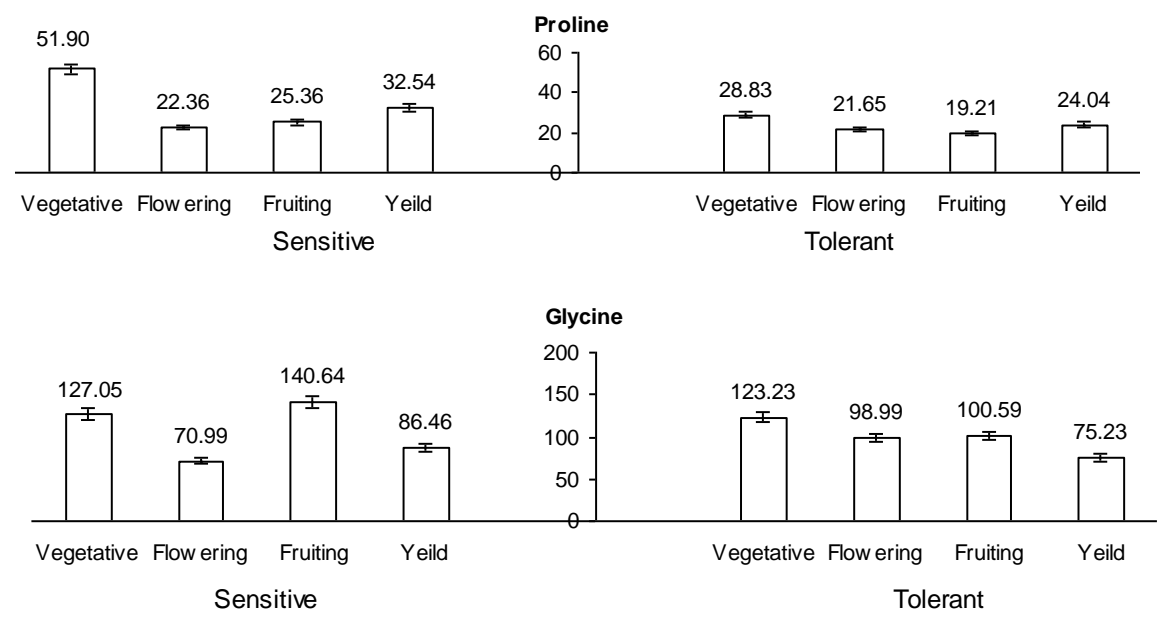

Fig. 6: Percent stimulation (PS) of amino acids of both salt-sensitive and salttolerant cultivars salinized with $9 \mathrm{dS} / \mathrm{m} \mathrm{NaCl}$ at different stages. Vertical bars represent standard error $(n=8)$.

\section{REFERENCES}

Ashraf M. (1994). Breeding for salinity tolerance in plants. Crit. Rev. Plant Sci., 13, 17-42

Ashraf M., Foolad M.R. (2007). Roles of glycine betaine and proline in improving plant abiotic stress resistance. Environmental and Experimental Botany, 59, 206-216

Azooz M.M., Shaddad M.A., Abdel-Latef A.A. (2004). The accumulation and compartmentation of praline in relation to salt tolerance of three sorghum cultivars. Ind. J. Plant Physiol., 9, 1-8

Delauney A.J., Verma D.P.S. (1993). Proline biosynthesis and osmoregulation in plants. Plant J., 4, 215-223

El-Bialy D.M.A. (2009). Physiological and molecular studies on the mechanism of salt tolerance in the lettuce plant. Ph.D. Thesis, Faculty of Science, Mansoura University, Mansoura, Egypt (in press)

El-Saht H. M. (1994). Reversal of osmotic stress effects by gibbberellic acid in Phaseolus vulgaris. J. Agric. Sci. Mans. Univ., 19, 3669-2682

El-Saht H. M. (1995). Sugars and acids as adaptive components in maize seedlings to salt. J. Environ. Sci., 10, 19-20

Fertris A. W. A. (1965). Serum glucose method without protein precipitation. Amer. J. Medic. Techno., 31, 17-21

Fougere F., Rudulier D.L., Streeter J.G. (1991). Effects of salt stress on amino acid, organic acid and carbohydrate composition on roots, bacteroids and cytosol of alfalfa (Medicago sativa L.), Plant Physiol., 96, 1228-1236.

Friedman T.E., Haugen G.E. (1943). The determination of keto acids in blood and urine. J. Biol. Chem., 147, 418-422 
Handa S., Bressan R. A., Handa A. K. , Carpita N.C. , Hasegawa P.M. (1983). Solutes contributing to osmotic adjustment in cultured plant cells adapted to water stress. Plant Physiol., 73, 834- 843

Handel E.V. (1968). Direct microdeterminations of sucrose.Analytical biochemistry, 22, 280 - 283

Hare P.D., Cress W.A. (1997). Metabolic implications of stress-induced praline accumulation in plants. Plant Growth Regul., 21, 79-102

Hasaneen M.N.A., Younis M.E., El-Bialy D.M.A. (2008). Plant growth, metabolism and adaptation in relation to stress conditions. XXII. Further studies supporting nullification of harmful effects of salinity in lettuce plants by urea treatment. Plant Soil Environ., 54 (3), 123-131

Hasaneen M.NA. (1978). Organic acid metabolism in storage organs. M.Sc. Thesis, Mansoura Univ., Mansoura, Egypt

Haseneen M. N. A., Younis M. E., El-Saht H. M. (1990). Plant growth, metabolism and adaptation in relation to stress conditions. XII Carbohydrate and acid accumulation in Phaseolus vulgaris and Zea mays stressed with sodium sulphate. Qater Univ. Sci. Bull., 10, 185197

Hsu S.Y., Hsu Y.T., Kao C.H. (2003). The effect of polyethylene glycol on proline accumulation in rice leaves. Biol. Plant., 46, 73-78

Jungklang J. (2005). Physiological and biochemical mechanisms of salt tolerance in Sesbania rostrata Berm and obem and Phaseolus vulgaris L.. Ph.D. Thesis, E. C. Agric. Univ. Teckuba, Japan

Kavi Kishore P.B., Sangam S., Amrutha R.N., Laxmi P.S., Naidu K.R., Rao K.R.S.S., Rao S., Reddy K.J., Theriappan P., Sreenivasulu N. (2005). Regulation of proline biosynthesis, degradation, uptake and transport in higher plants: its implications in plant growth and abiotic stress tolerance. Curr. Sci., 88, 424-438

Kerepesi I., Galiba G. (2000). Osmotic and salt stress-induced alteration in soluble carbohydrate content in wheat seedlings. Crop Sci., 40, 482487

Maas E.V., Hoffman G.F. (1977). Crop salt tolerance-currentassessment. J Irr Drain Div-ASCE, 103,115-134

Maggio A., Raimondi G., Martino A. , De Pascale S. (2007). Salt stress response in tomato beyond the salinity tolerance threshold Environmental and Experimental Botany, 59, 276-282

Mansour, M.M.F.(2000). Nitrogen containing compounds and adaptation of plants to salinity stress. Biol. Plant., 43, 491-500

McKersie BD, Leshem YaY (1994). Stress and stress coping in cultivated plants. Kluwer Academic Publishers, Dordrecht, The Netherlands

Mostafa D.M. (2004). Metabolic imbalance and salinity tolerance of two maize cultivars. M.Sc. Thesis. El-Minia Univ. Elminia, Egypt 1-195

Muting R.D., Kaiser H.Z. (1963). Spectrophotometric method of determining of amino- $\mathrm{N}$ in biological materials by means of ninhydrin reaction. Hoppe-Seyler's Z. physiol. Chem., 323, 276-279

Parida A.K., Das A.B., Mittra B. (2003). Effect of $\mathrm{NaCl}$ stress on the structure, pigment complex composition and photosynthetic activity of mangrove Bruguiera parviflora chlorplasts. Photosynth., 41, 191-200. 


\section{Younis, M. E. et al.}

Rabe E. (1990). Stress physiology: the functional significance of the accumulation of nitrogen-containing compounds. J. Hortic Sci., 65, 231-243

Roe J. H. (1934). A colorimetric method for the determination of fructose in blood and urine. J. Biol. Chem. ,107,15

Satoh R., Nakashima K., Seki M., Shinozaki K., Yamaguchi-Shinozaki K. (2002). ACTCAT, a novel cis-acting element for proline- and hypoosmolarity-responsive expression of the ProDH gene encoding proline dehydrogenase in Arabidopsis. Plant Physiol., 130, 709- 719

Snell F. D., Snell C. T. (1949). Colorimetric methods of analysis, II Nostrand, New York, Pp. 804- 808

Snell F. D., Snell C.T. (1954). Colorimetric methods of analysis, IV New York, van Nostrand.Pp. 310-316

Srinivas V., Balasubramanian D. (1995). Proline is a protein-compatible hydrotrope. Langmuir, 11, 2830-2833

Tammam A. A., Abou Alhamd M. F., Hemeda M. M. (2008). Study of salt tolerance in wheat (Triticum aestium L.) cultivar Banysoif 1. Australian Journal of Crop Science., 1(3),115-125

Venekamp J. H. (1989). Regulation of cytosol acidity in plants under conditions of drought. Physiol. Plant., 76, 112-117

Yemm E.W. and Willis A.J. (1954). The estimation of carbohydrates by anthrone. Biochem. J., 57, 508-514

Yemm, E.W. and Willis, A.J. (1956). The respiration of barley plants. IX. The metabolism of roots during the assimilation of nitrogen, New Phytol., 55, 229-252

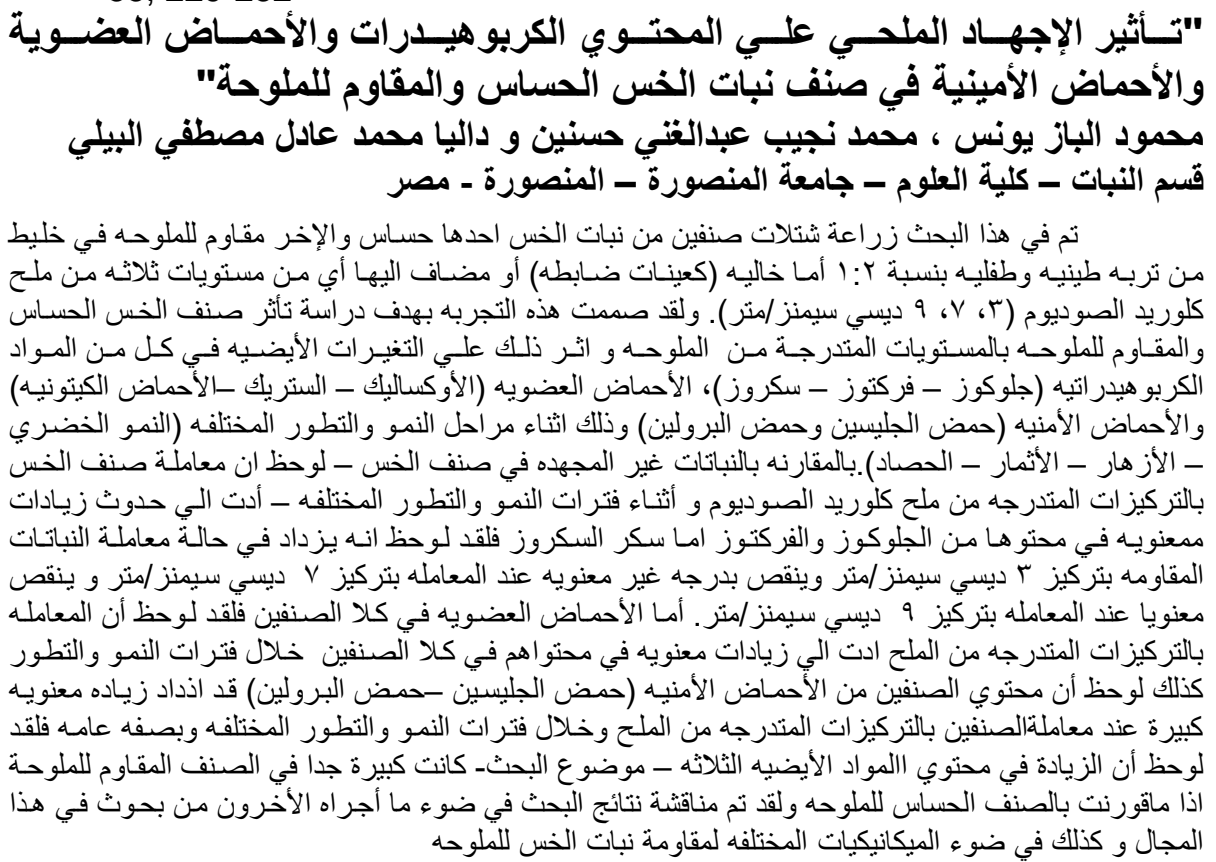

